Original Research Paper

\title{
Factors Affecting the Response to Interferon Alpha Therapy in Egyptian HCV Patients
}

\author{
${ }^{1}$ Naglaa F. Alhusseini, ${ }^{2}$ Fathy M. Serry, ${ }^{2}$ Ashraf A. Kadry and ${ }^{2}$ Heba Khairy \\ ${ }^{I}$ Department of Medical Biochemistry, Faculty of Medicine, Benha University, Egypt \\ ${ }^{2}$ Department of Microbiology and Immunology, Faculty of Pharmacy, Zagazig University, Egypt
}

Article history

Received: 21-04-2015

Revised: $22-06-2015$

Accepted: 07-08-2015

Corresponding Author:

Naglaa F. Alhusseini

Department of Medical

Biochemistry, Faculty of Medicine,

Benha University, Egypt

Email: nagla.alhusseini@fmed.bu.edu.eg

\begin{abstract}
Hepatitis C Virus (HCV) infection is one of the main causes of chronic liver disease worldwide. Egypt has the highest prevalence of Hepatitis C Virus (HCV) in the world, estimated nationally at $14.7 \%$. knowledge of the predictors of Sustained Viral Response (SVR) to Pegylated Interferon (PEG-INF) and Ribavirin (RBV) therapy in patients with chronic hepatitis $\mathrm{C}$ is crucial for selecting patients who would benefit most from therapy especially in developing country as Egypt where the highest percentage of treatment cost funded by government. This study was performed on Egyptian patients with chronic active hepatitis $\mathrm{C}$ who were prepared for receiving a course of treatment with: Interferon (PEG IFN) and ribavirin for 48 weeks. We aimed to find more predictive markers those can help clinicians to choose the most effective treatment program for each patient. Assessment of HLA-DRB1, HLA-DQB1 genes by Sequence Specific Primer (SSP) PCR, interleukin-10 (IL-10) by ELISA technique and Serum HCV RNA load by TaqMan Real Time RT-PCR technology were done. We found that sustained responders were significantly among DRB1*13 allele and DQB1*02 typing $(\mathrm{p}<0.001)$. DRB1*07 allele only appeared with responded patients. Relations were found between response to treatment and lower IL-10 level and lower Body Mass Index (BMI) but not sufficient to reach to significant value. In conclusion, we emphasize the importance of the use of pharmacogenomic data in the treatment of patients. HLA-DRB1*07, HLA-DRB1*13 and HLA-DQ02 alleles can predict the response to $\mathrm{HCV}$ combined therapy. The data generated from our study may be helpful in future for clinicians to predict the treatment outcome for HCVseropositive individuals in Egypt.
\end{abstract}

Keywords: HCV, HLA Typing, IL 10, Interferon, Ribavirin

\section{Introduction}

Hepatitis C Virus (HCV) infection is one of the main causes of chronic liver disease worldwide (Lavanchy, 2011). HCV belonging to the family Flaviviridae signifies to be an entire global dilemma which parades the variability of genome translated into six genotypes and more than 80 subtypes (Baldo et al., 2008). The long-term impact of $\mathrm{HCV}$ infection is highly variable, ranging from minimal histological changes to extensive fibrosis and cirrhosis with or without Hepatocellular Carcinoma (HCC). The number of chronically infected persons worldwide is estimated to be about 160 million, but most are unaware of their infection (EASL, 2014). In fact, Egypt has the largest epidemic of $\mathrm{HCV}$ in the world with an overall serum positive prevalence of $14.7 \%$ as reported by the Egyptian demographic health survey (El-Zanaty and Way, 2009). Hepatitis C Virus genotype $4(\mathrm{HCV}-4)$ is the most common variant of the hepatitis $\mathrm{C}$ virus (HCV) in the Middle East and Africa, particularly Egypt. This region has the highest prevalence of $\mathrm{HCV}$ worldwide, with more than $90 \%$ of infections due to genotype-4 (Kamal and Nasser, 2008). The primary goal of HCV therapy is to cure the infection. A Sustained Virological Response (SVR) is defined as undetectable HCV RNA 12 weeks (SVR12) or 24 weeks (SVR24) after treatment completion EASL (2014). Until 2011, the combination of pegylated 
interferon (IFN)- $\alpha$ and ribavirin for 24 or 48 weeks was the approved treatment for chronic hepatitis C EASL (2011). In 2011, telaprevir and boceprevir were licensed for use in HCV genotype 1 infection. These two drugs are first-wave, first-generation Direct-Acting Antivirals (DAAs). Both target the $\mathrm{HCV}$ NS3/4A serine protease and are thus referred to as protease inhibitors. Both telaprevir and boceprevir must be administered in combination with pegylated IFN- $\alpha$ and ribavirin (Poordad et al., 2011) and (Zeuzem et al., 2011). However, the side effect profiles of these triple combination therapies are not favorable and the costs per SVR in patients with advanced hepatic fibrosis are such that they should ideally no longer be used in patients infected with HCV genotype 1, as soon as other, more efficacious and better-tolerated options are available. Sofosbuvir, a nucleotide analogue inhibitor of $\mathrm{HCV}$ RNA-dependent RNA polymerase, has been approved in January 2014. Simeprevir, a second-wave, first generation NS3/4A protease inhibitor will be approved in May 2014. Daclatasvir, an NS5A inhibitor, is likely to be approved in September 2014. Other drugs may be approved later in 2014 or in 2015 (EASL, 2014). However, response to treatment is not uniform across all populations and is dependent on various viral and host factors (Dienstag and McHutchison, 2006). So the ability to accurately predict the response of $\mathrm{HCV}$ patients to antiviral therapy is of great interest Lee and Abdo (2003). Host genetic factors are proposed to be governing the pathology of disease progression or regression along with the viral and environmental factors. Interplay of HLA restricted $\mathrm{T}$ lymphocytes, antibody-secreting B-lymphocytes, NK cells and cytokines, conditions the immune response to viral infections. Effective presentation of viral antigens to CD4 $+\mathrm{T}$ cells and CD8 $+\mathrm{T}$ cells by HLA class II and class I molecules respectively, is the key regulation of optimum immune response against viral infection and further dictates viral clearance or persistence Martin and Carrington (2005). Also the balance of the two arms of the immune system, the innate and the adaptive one, which interact with each other also through a cytokine network, plays an important role in the pathogenesis and clinical outcome of HCV-related hepatitis Cavaillon (2001). IL-10 involved in a Th2 response and as markers of inflammation. Torre et al. (2004) suggested a pivotal role for IL-10 in orchestrating the antiviral immune response. Its early decline can favor the shift from a Th2 to a Th1 immune response, which has been shown to be associated with a long-term virological response to treatment. Thus, the aims of this study were to assess pre-treatment predictors of response in patients with $\mathrm{CHC}$ infection.

\section{Patients and Methods}

\section{Patients}

A series of 85 Egyptian patients with chronic active hepatitis $\mathrm{C}$ previously untreated referred to Viral Hepatitis Center, Benha city, Egypt- from June 2012 to January 2013- was enrolled into the study. The study protocol was approved by the Ethical Review Committee (ERC) of Faculty of Medicine, Benha University and by National Committee for control of viral hepatitis of Egyptian Ministry of Health, Egypt and written informed consent was obtained from all participants.

Patients were assigned randomly to receive a course of treatment of 12 weeks with: $180 \mu \mathrm{g}$ once weekly for Pegylated Interferon $\alpha$ and coupled with $800 \mathrm{mg}$ of ribavirin. All patients were hepatitis B surface antigen and HIV antibody negative.

\section{Sampling}

Peripheral venous blood was collected from each patient by venous puncture before the beginning and after 3 months (12 weeks) of treatment with peginterferon alpha. About $3 \mathrm{~mL}$ from blood sample was put immediately into sterile vaccutainer tube containing EDTA, divided into 2 eppendof tubes. For serum collection, about $3 \mathrm{~mL}$ blood collected into plain sterile vaccutainer tube was allowed to clot and centrifuged for $10 \mathrm{~min}$ at $5000 \mathrm{rpm}$. The serum was removed from the clot, as soon as possible to avoid hemolysis. Both serum and blood were stored at $-80^{\circ} \mathrm{C}$ until required for further processing.

Baseline characteristics of subjects included clinical history, physical examination, routine hematological, biochemical, serological and virological tests including $\mathrm{HCV}$ qualitative and quantitative Polymerase Chain Reaction (PCR).

\section{Virological Assessment}

Serum HCV RNA was extracted using an automated extraction system by QIAamp Viral RNA Mini Kit and QIAcube automatic extractor machine from, Qiagen GmbH. HCV detection and quantification were performed using TaqMan RT-PCR master mix Artus HCV RG RT-PCR Qiagen GmbH. Absolute quantitation of RT-PCR was done using ABI7900 Real time machine, Applied Biosystem USA. According to European Association for the Study of the Liver (ESAL), 2014. The endpoint of therapy is a Sustained Virological response SVR, defined by undetectable HCV RNA 12 weeks (SVR12) or 24 weeks (SVR 24) and after the end of therapy (48weeks). 
HLA-DRB1 and HLA-DQB1 Genes Amplification Using Polymerase Chain Reaction Sequence Specific Primer (PCR-SSP)

The human leukocyte antigens included in the study were as follows: DRB $1 * 07$, DRB $1 * 13$ and DQB $1 * 02$. The amplification was done direct without DNA extraction by using KAPA Blood PCR kit (BIOSYSYTEM $®$, USA) Alhusseini et al. (2012). Primers used in HLA typing were as following: DRB1*07 F-TCC TGT GGC AGG GTA AGT AT. RCGT TGC ACT GTG AAG CTC TC. DRB1*13: FGTT TCT TGG AGT ACT CTA CGT C. R- TGT TCC AGT ACT CGG CGT T. and DQB1*02: F- CAC CTG CAG TCG GAG CTC CAA CTG GTA. R- GGA TTT CGT GTA CCA GTT TAA GG. PCR was performed using thermal cycler ( $G$ storm, UK). The first cycle included initial extended steps of denaturation at $95^{\circ} \mathrm{C}$ for $5 \mathrm{~min}$ followed by 35 cycles of denaturation at $95^{\circ} \mathrm{C}$ for $30 \mathrm{sec}$, annealing at $\left(48^{\circ} \mathrm{C}\right.$ for DRB1 ${ }^{*} 07$ allele, $50^{\circ} \mathrm{C}$ for DRB $1 * 13$ and $55^{\circ} \mathrm{C}$ for $\mathrm{DQB} 1 * 02$ ) for $30 \mathrm{sec}$ and elongation at $72^{\circ} \mathrm{C}$ for one min, followed by a final extended elongation step at $72^{\circ} \mathrm{C}$ for $1 \mathrm{~min}$.

\section{Analysis of the Amplified Products}

After completion of the PCR program, the obtained amplified products were centrifuged at 14,000 rpm speed to obtain the most compact pellet of organicdebris (and facilitate recovery of the amplicon containing supernatant. The amplified DNA was analyzed by electrophoresis. About $10 \mu \mathrm{L}$ of each reaction mixture and 1000 Base Pair (BP) ladder (Molecular weight marker) was separated on $2 \%$ agarose gel containing 0.3 ug mL $\mathrm{mL}^{-1}$ of ethidium bromide. The bands were visualized using UV Transilluminator (254 $\mathrm{nm}$ ) and photographed using a digital camera 8 mega pixel. The image was transferred to be analyzed by computer software (Alpha In no Tech Gel Documentation System).

\section{Assays for IL-10}

Serum levels of IL-10 were measured using a commercially available ELISA according to the manufacturer's instructions. (Ray Bio ${ }^{\circledR}$ Human, Georgia).

\section{Liver Histology}

Pre-treatment liver biopsy for pathological grading and staging was done for all patients. The hepatic inflammation (grade) and fibrosis (stage) in the biopsy specimens were evaluated according to the METAVIR scoring system.

\section{Detection of Schistosoma Antibodies}

Indirect Heme-Agglutination assay (IHA) was used for detection of schistosoma antibodies in human serum by using Schisto-IHA-Fast ${ }^{\mathrm{TM}}$ kit.

\section{Calculation of Body Mass Index (BMI)}

It is calculated by the following equation Bhaskaran et al. (2014):

$$
\mathrm{BMI}=\frac{\operatorname{weigt}(\mathrm{kg})}{(\operatorname{height}(\mathrm{m}))^{2}}
$$

\section{Statistical Analysis}

The collected data were analyzed using SPSS version 16 software. Categorical data were presented as number and percentages using chi square test $\left(\mathrm{X}^{2}\right)$ of significance for their analysis. Quantitative variables were expressed as mean and SD, using student "t" test for their analysis if normally distributed, while non parametric data were analyzed using Mann Whitney U test and Spearman's correlation coefficient.

\section{Results}

Baseline characteristics and clinical profile of the studied patients are presented in Table 1 and 2.

Table 1. Baseline characteristics of the studied patients

\begin{tabular}{lcr}
\hline Variable & No./85 & $\%$ \\
\hline Gender & 54 & 63.5 \\
Male & 31 & 36.5 \\
Female & 8 & \\
Metavir score degree of fibrosis (F) & 62 & 72.9 \\
F1 & 15 & 17.6 \\
F2 & & \\
F3 & 45 & 52.9 \\
Metavir score histological activity (A) & 34 & 40.0 \\
A1 & 6 & 7.1 \\
A2 & & \\
A3 & 62 & 72.9 \\
Schistosoma antibodies & 23 & 27.1 \\
Negative & & \\
Positive & 20 & 23.5 \\
Viral load at the beginning of treatment week 0 & 37.6 \\
Low & 32 & 20.0 \\
Moderate & 17 & 18.8 \\
High Moderate & 16 & \\
High &
\end{tabular}

Table 2. Baseline clinical profile of the studied patients

\begin{tabular}{ll}
\hline Variable & Mean \pm Sd (Range) \\
\hline Age: Year & $35.4 \pm 10.9(19-59)$ \\
Fasting Blood Glucose: Mg/Dl & $99.8 \pm 56.2(68-489)$ \\
Creatinine: $\mathrm{Mg} / \mathrm{Dl}$ & $1.07 \pm 0.89(0.51-6.7)$ \\
Albumin G/Dl & $4.4 \pm 0.41(3.4-5.2)$ \\
Alkaline Phosphatase U/L & $150.3 \pm 57.6(30-321)$ \\
Alt U/L & $43.0 \pm 25.3(8-183)$ \\
Ast: U/L & $46.6 \pm 31.03(9-191)$ \\
Total Bilirubin Mg/Dl & $0.76 \pm 0.29(0.2-1.5)$ \\
Wbcs Cell*10 $10^{3} / \mu \mathrm{L}$ & $6.98 \pm 2.4(3.7-16.2)$ \\
Hemoglobin $(\mathrm{Hb}) \mathrm{G} / \mathrm{Dl}$ & $14.3 \pm 1.5(10.8-17.8)$ \\
\hline Blood platelets count*10 & $3 / \mu \mathrm{L} 222.6 \pm 62.3(100-374)$
\end{tabular}




\section{Response to Treatment}

From 85 patients 74 patients $(87.06 \%)$ responded to standard therapy, i.e., had a Sustained Virological Response (SVR), while 11 patients (12.04\%, 9 males and 2 females) did not respond to the therapy (non-SVR).

\section{HLA Allelic Types}

The distribution of HLA types among patients is shown in Fig. 1 and 2. The result revealed that there was a significant difference in base line viral load only among
$\mathrm{DRB} 1 * 07$ allele typing $(\mathrm{p}=0.04)($ Table 3$)$. There was a significant difference between DRB $1 * 13$ allele and DQB $1 * 02$ typing $(\mathrm{p}<0.001)$ with response to treatment at the $12^{\text {th }}$ week where DRB $1 * 07$ allele referred to patients responded to the treatment (Table 4 and 5). Table 6 showed that there was a significant difference among DQB1*02 typing for both degree of fibrosis and histological activity but there is no significant difference among DRB1*07 allele and DRB1*13 typing for both degree of fibrosis and histological activity.

Distribution of HLA typing

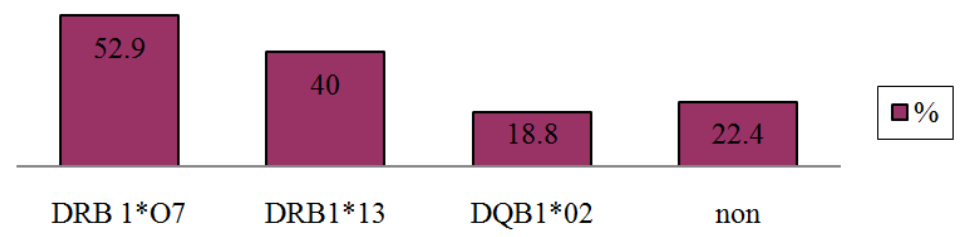

Fig. 1. HLA distribution among the HCV patients

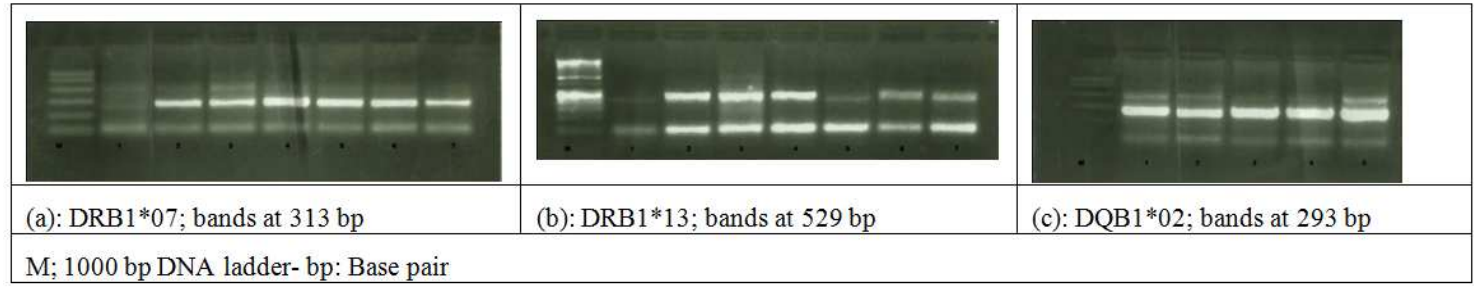

Fig. 2. Gel electrophoresis of the amplified products of HLA-typing genes

Table 3. The relation between baseline Viral load (IU/ml) and HLA typing among the studied patient

\begin{tabular}{|c|c|c|c|}
\hline HLA typing & $\begin{array}{l}\text { Baseline Viral load } \\
\text { Mean } \pm \mathrm{SD}\left(\times 10^{5}\right)\end{array}$ & "Z" of MWU test & $\mathrm{p}$ \\
\hline $\mathrm{DRB} 1 * 07(\mathrm{~N}=45)$ & $9.05 \pm 14.6$ & 2.03 & $0.04 *$ \\
\hline $\mathrm{DRB} 1 * 13(\mathrm{~N}=34)$ & $6.8 \pm 9.04$ & 0.47 & 0.64 \\
\hline DQB1*02 $(\mathrm{N}=16)$ & $10.8 \pm 20.8$ & 0.28 & 0.77 \\
\hline
\end{tabular}

Table 4. Relation between each HLA allele and response to treatment at the $12^{\text {th }}$ week

\begin{tabular}{llllll}
\hline Allele & No./85 & Response No. $(\%)$ & Non response No. (\%) & Z & p \\
\hline DRB1*13 & 34 & $33(97.1)$ & $1(2.9)$ & 16.2 & $<0.001^{*}$ \\
DRB1*07 & 45 & $45(100)$ & $0(0)$ & 3.2 & $<0.001^{*}$ \\
DQB1*02 & 16 & $13(81.2)$ & $3(18.8)$ & 3 & \\
\hline
\end{tabular}

*: Significant $\mathrm{p}$ value

Table 5. Relation between HLA type and response to treatment at the $12^{\text {th }}$ week

\begin{tabular}{|c|c|c|c|c|c|c|}
\hline HLA type & No. $/ 85$ & $\%$ & Responded & Non responded & $\mathrm{Z}$ & $\mathrm{P}$ \\
\hline $\mathrm{DRB} 1 * 13$ & 11 & 12.9 & $10 / 11$ & $1 / 11$ & 4.72 & $<0.001 *$ \\
\hline $\mathrm{DRB} 1 * 07$ & 21 & 24.7 & $20 / 21$ & $1 / 21$ & 9.74 & $<0.001 *$ \\
\hline DQB $1 * 02$ & 8 & 9.4 & $7 / 8$ & $1 / 8$ & 3.20 & $<0.001^{*}$ \\
\hline $\mathrm{DRB} 1 * 13 \& \mathrm{DRB} 1 * 07$ & 18 & 21.2 & $17 / 18$ & $1 / 18$ & 8.20 & $<0.001 *$ \\
\hline $\mathrm{DRB} 1 * 13 \& \mathrm{DQB} 1 * 02$ & 2 & 2.4 & $1 / 2$ & $1 / 2$ & 0.00 & 1.0 \\
\hline $\mathrm{DRB} 1 * 07 \& \mathrm{DQB} 1 * 02$ & 3 & 3.5 & $2 / 3$ & $1 / 3$ & 0.61 & 0.55 \\
\hline $\mathrm{DQB} 1 * 02, \mathrm{DRB} 1 * 07 \& \mathrm{DRB} 1 * 13$ & 3 & 3.5 & $3 / 3$ & $0 / 3$ & 2.44 & $0.014 *$ \\
\hline Non typed & 19 & 22.4 & $14 / 19$ & $5 / 19$ & & \\
\hline
\end{tabular}

*: Significant 


\section{Serum Levels of IL-10}

Correlation between IL10 and each of baseline viral load, Metavir score (degree of fibrosis (F) and histological activity score (A) gave a weak non significant positive correlation $\mathrm{r}=0.37,0.47$ and 0.16 respectively $p>0.05$. The level of IL-10 was significantly high among male patients $(0.49 \pm 0.3)$ when compared to female patients $(0.37 \pm 0.20)(\mathrm{p}=$ 0.029). But the mean level of IL-10 as regard to response to treatment at the 12 th week, showed that it relatively lower in patients responded to treatment $(0.42 \pm 0.23)$ comparing with non responded patients $(0.51 \pm 0.44)$ however, this difference was not sufficient to reach to significant level $(\mathrm{p}>0.05)$.

\section{Other Factors Predictive of SVR}

According to our data there are some factors associated with SVR as blood platelets count and blood glucose those show significant correlation with treatment response ( $p=0.048$ and 0.001 respectively) (Fig. 3 and 4).

There was no significant correlation between the presence of schistosoma antibodies and the outcome of the treatment $(\mathrm{p}=1.0)($ Table 7). Also Metavir score among studied subjects with both histological activity score (A) and degree of fibrosis (F) didn't have any significant correlation ( $p=0.28$ and $p=0.32$ respectively).

In comparing BMI for responding and non responding patients the result showed that there was an increase in BMI in non responder patients $(27.98 \pm 1.71)$ as compared to $26.32 \pm 4.8$ in responder, but this relation not reach to significant value $(\mathrm{p}>0.05)$.

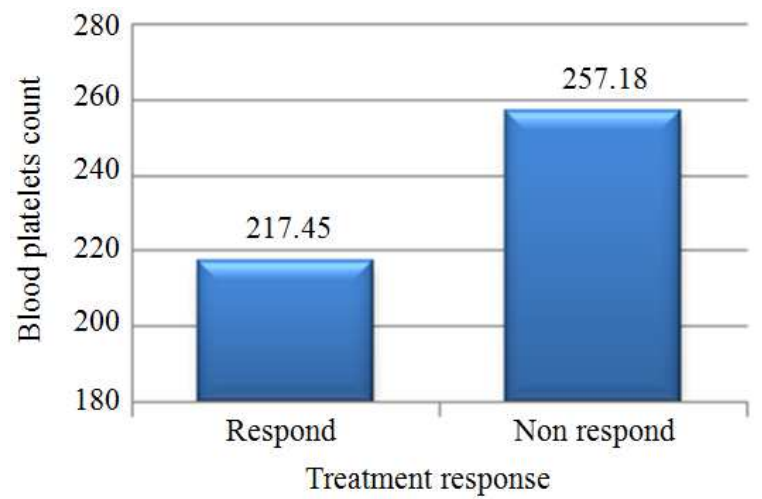

Fig. 3. Mean value of Blood Platelets count and treatment response

150.4

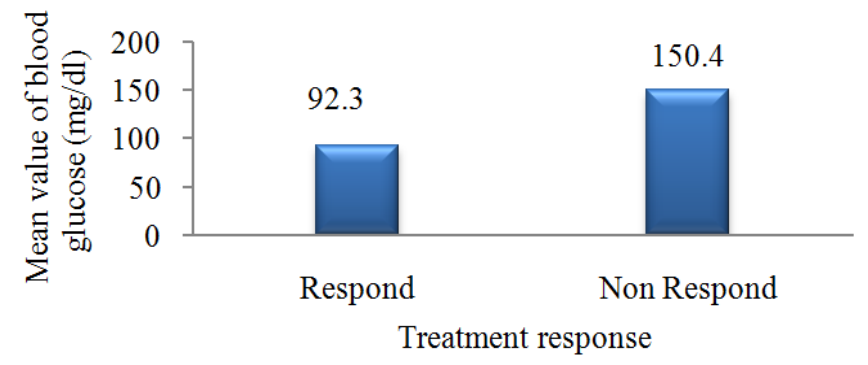

Fig. 4. Mean value of blood glucose $(\mathrm{mg} / \mathrm{dl})$ and treatment response

Table 6. Relation between metavir score (degree of fibrosis and histological activity) and HLA typing among the studied patients

\begin{tabular}{llll}
\hline Metavir score & DRB1*07 No.(\%) & DRB1*13 No.(\%) & DQB1*02 No.(\%) \\
\hline F1 & $2 / 8(4.4 \%)$ & $3 / 8(8.8 \%)$ & $0 / 8(.0 \%)$ \\
F2 & $35 / 62(77.8 \%)$ & $27 / 62(79.4 \%)$ & $6 / 62(37.5 \%)$ \\
F3 & $8 / 15(17.8 \%)$ & $4 / 15(11.8 \%)$ & $10 / 15(62.5 \%)$ \\
$X^{2}$ & 2.8 & 1.46 & 27.7 \\
p & 0.24 & 0.48 & $<0.0011^{*}$ \\
A1 & $21 / 45(46.7 \%)$ & $17 / 45$ & $2 / 45(12.5 \%)$ \\
A2 & $20 / 34(44.4 \%)$ & $15 / 34(44.1 \%)$ & $8 / 34(23.5 \%)$ \\
A3 & $4 / 6$ & $2 / 6$ & $0 / 6$ \\
$X^{2}$ & 0.44 & 0.44 & 32.5 \\
p & 1.64 & 0.8 & $<0.001 *$ \\
\hline
\end{tabular}

$\mathrm{X}^{2}$ : Kai Square, *: Significant

Table 7. The relation between schistosoma antibodies presence and response to treatment at the 12th week

\begin{tabular}{lll}
\hline & Treatment response & \\
Schistosoma & ------- & Non respond \\
Antibodies presence & Respond & $8 / 62(12.9 \%)$ \\
Absent & $54 / 62(87.1 \%)$ & $3 / 23(13 \%)$ \\
\hline Present & $20 / 23(87.0 \%)$ & \\
\hline
\end{tabular}

Fisher's $\mathrm{p}=1.0$ 


\section{Discussion}

The goal of therapy is to eradicate HCV infection in order to prevent the complications of HCV-related liver and extra-hepatic diseases, including hepatic necroinflammation, fibrosis, cirrhosis, decompensation of cirrhosis, hepatocellular carcinoma and death. The endpoint of therapy is an SVR, defined by undetectable HCV RNA 12 weeks (SVR12) or 24 weeks (SVR24) after the beginning of therapy, as assessed by a sensitive molecular method with a lower limit of detection $<15$ IU $\mathrm{mL}^{-1}$ Martinot-Peignoux et al. (2010).

Interplay of HLA restricted T lymphocytes, antibodysecreting B-lymphocytes, NK cells and cytokines, conditions the immune response to viral infections. Effective presentation of viral antigens to $\mathrm{CD} 4+\mathrm{T}$ cells and $\mathrm{CD} 8+\mathrm{T}$ cells by HLA class II and class I molecules respectively, is the key regulation of optimum immune response against viral infection and further dictates viral clearance or persistence. HLA allele association with interferon treatment response seems to differ for chronic HCV infections in global populations. This can be attributed to differences in the antigenic determinants of viruses and consequently differences in the HLA molecules involved Gomaa et al. (2014).

The present study indented to discuss the effect of HLA class II alleles as multiple studies have reported that class II alleles may play a role in the natural history of HCV infection (Corghi et al., 2008), viral load (Wang et al., 2005) and even in the curative effect of antiviral therapy Jiao and Wang (2003). It is generally accepted that cellular immune responses play an important role in viral clearance and disease resolution. Clearance of the virus during acute infection has been shown to be associated with strong and sustained HCVspecific $\mathrm{CD} 4+$ and $\mathrm{CD} 8+\mathrm{T}$-cell responses. These responses depend on the presentation of $\mathrm{HCV}$ antigens in the context of HLA class II molecules. Therefore, the differences in HLA class II alleles may strongly influence the clinical course of hepatitis C. Hong et al. (2005).

The results showed that DRB1*07 was the most prevalence allele among the studied patients with percentage of $52.9 \%$ followed by DRB $1 * 13(40 \%)$ then DQB $1 * 02(18.8 \%)$. It was noticed that there was a significant difference in base line viral load among DRB $1 * 07$ allele among patients with low viremia but there was no significant difference in base line viral load among DQB $1 * 02$ and DRB $1 * 13$ types.

The highest significant $(\mathrm{p}<0.001)$ treatment response $(100 \%)$ was found with DRB $1 * 07$ allele type then DRB1*13 (97.1\%) where the highest percentage of non responded patients was noticed among DQB $1 * 02$ type $(81.3 \%)$.

Fanning et al. (2001) reported that individuals who possess the alleles DRB1*0701 and/or DQB1*0201 have a relatively stable viral load over time. Also DRB $1 * 07$ and DQB $1 * 02$ were found by Wawrzynowicz-Syczewska et al. (2000) in responsive patients and Jiao and Wang (2003) found a higher response rate to IFN in patients with the HLADRB $1 * 07$ allele where Martinetti et al. (2006) reported that DRB $1 * 13$ allele was significant in protection from chronic HCV especially the protection from vertical transmission in infants born to $\mathrm{HCV}$ positive mothers.

On the other hand, some study found that DRB $1 * 07$ and DRB $1 * 13$ associated with disease persistence even after IFN. Hong et al. (2005; Thio, 2008; Yee et al., 2012); observed a higher prevalence of HLA DRB $1 * 07$ in non-SVR compared with SVR patients. Yosry et al. (2011) found that DRB1*15 and DRB $1 * 13$ were the only two significant independent risk factors for $\mathrm{HCV}$ infection in Egyptian children. However, this could be due to ethnically and geographically different distribution of class II genes which affect the outcome of HCV infection.

To correlate the HLA type with the disease progress the result showed there was a significant difference among DQB $1 * 02$ type for both degree of fibrosis and histological activity but there was no significant difference among DRB $1 * 07$ and DRB $1 * 13$ types for both.

A high a significant difference between DQB $1 * 02$ and metavir score $(\mathrm{F}$ and $\mathrm{A})$ was observed for that a lot of study associated between DQB $1 * 02$ with Hepatocellular Carcinoma as El-Chennawi et al. (2008) concluded that the DRB $1 * 04$ and $\mathrm{DQB} 1 * 02$ alleles might be risk factors for the occurrence of HCC also found DQB $1 * 02$ to be associated with disease persistence even after IFN. The present study also investigated the effect of Interleukin (IL)-10 level on response to treatment and its relation with disease state.

IL-10 is an important immunoregulatory cytokine produced by many cell populations even in liver itself Zhang and Wang (2006) Interleukin-10 (IL-10) described as a cytokine synthesis inhibitory factor for $\mathrm{T}$ lymphocytes produced by T helper 2 (Th2) cell clones, can inhibit interferon (IFN)- $\gamma$ synthesis in Th1 cell clones.

In this study the correlation between IL10 level, baseline viral load and Metaviir score ( $\mathrm{F}$ and $\mathrm{A}$ ) give a Weak non significant positive correlation. However, the relation between IL 10 level and gender was significant $(\mathrm{p}=0.029)$.

Paladino et al. (2006) demonstrate a gender effect associated with the susceptibility to develop a persistent $\mathrm{HCV}$ infection and a chronic liver disease together with an inhibition of fibrogenic process in women carrying the high IL-10 producer genotype (GG).

Relation between IL 10 and response to treatment even it was no significant $(p=0.70)$, but we can note the high level of IL-10 in non responded patient. Umemura et al. (2011) who identified a high baseline 
levels of IL-10 ( $\mathrm{p}<0.001)$ was significantly associated with a Non-Virological Response (NVR) in their cohort. On the other hand, a 12-month IL-10 therapy in patients with advanced fibrosis led to increased levels of serum HCV RNA and a reduction in fibrosis score suggesting that high levels of IL-10 not only decrease fibrogenesis but also lead to an increased HCV viral burden. This could be achieved by decreasing the number of $\mathrm{HCV}$ specific CD4 and CD8 gamma interferon-secreting $\mathrm{T}$ cells and polarizing the immune response towards a Th2dominant profile (Nelson et al., 2003).

Similarly, it has been published that the antibodyinduced blockage of the IL-10 receptor generates a favorable balance of CD4 T-cell response to HCV. Also, this anti-IL-10 receptor reverses the inhibitory effect of IL-10 on HCV-specific T-cell proliferation, demonstrating the major role of IL-10 in suppressing antiviral T-cell responses (Rigopoulou et al., 2005).

Even the data give negative result regarding IL-10 level, it does not mean that IL-10 level is not important but that result may be due to small number of studied sample which include small number of non responder with un equal number of males and females.

The current study investigated the effect of schistosomal co-infection on $\mathrm{HCV}$ treatment response because $\mathrm{HCV}$ and schistosomiasis co-infection are major public health problems in Egypt. From 85 patients enrolled in the study, 23 patients $(27.1 \%)$ showed positive result for schistosoma antibodies test and 62 patients $(72.9 \%)$ showed negative result. The relation between the presence of schistosoma antibodies and treatment response shows no significant relation as the responded patient represented a percentage of $87.1 \%$ from negative schistosoma antibodies patient and $87 \%$ from positive patients so schistosomal co-infection did not affect the response.

Derbala et al. (2011) also concluded that schistosomal co-infection did not enhance liver pathology and did not affect response rate. On the other hand, Abdel-Rahman et al. (2013) found that Positive schistosomal serology has no effect on fibrosis staging but is significantly associated with failure of response to HCV treatment despite antischistosomal therapy, as that early virological response EVR, virological response at week 24 and SVR were significantly higher in patients with negative schistosomal serology. This finding may be attributed to coinfected patients with a downregulated immune response to $\mathrm{HCV}$ leading to reduced IFN $\gamma$, interleukin (IL)- 4 and IL-10 secreted by HCVspecific T cells. Early reports by Kamal et al. (2000) using standard IFN in the treatment of chronic HCV patients reported that Egyptian patients with co infections have higher HCV RNA titers, more advanced liver disease, more hepatic complications and greater mortality rates than those infected with $\mathrm{HCV}$ alone.
Liver biopsy assessment in this study was estimated by metavir score. Studied subjects showed no significant relation with both histological activity score (A) and degree of fibrosis $(\mathrm{F})$ with treatment response.

In agreement with our study, The study of Kamal et al. (2005) showed that only age of $>40$ years and pretreatment viral load of $>2$ million copies $/ \mathrm{mL}$, can independently predict SVR and not the pre-treatment liver pathology but Hasan et al. (2004), found Patients with cirrhosis or severe fibrosis had significantly lower SVR rate compared to those with mild or no fibrosis. Myers et al. (2012) concluded that there is no absolute fibrosis threshold that should be used to preclude antiviral therapy and prompt initiation of treatment should be considered in patients with advanced liver fibrosis (F3 or F4 according to the Metavir classification) as these patients are at the highest risk of HCV-related complications including liver failure and HCC.

Some authorities as Dienstag (2002) forego that a baseline liver biopsy was not always recommended before onset of treatment in patients with genotypes 2 and 3 as their response is so high and the duration of therapy so much shorter whereas patients with others genotypes obtain biopsy specimens before therapy because baseline histology is a predictor of response to therapy that is independent of genotype.

In the current study Alanine Transaminase (AST), Aspartate Transaminase (ALT) showed non significant relation with treatment response that results supported by recommendation of the AGAI (2006) about AST and ALT level which is an important component of the diagnostic evaluation in patients with chronic hepatitis $\mathrm{C}$, but not their elevation is a requirement for therapy because approximately $30 \%$ of patients with chronic HCV infection show Persistently Normal ALT (PNALT). Although formerly referred to as 'healthy' or 'asymptomatic' HCV carriers and thus historically excluded from antiviral treatment, it has now become clear that they are at risk for developing significant liver disease; up to $20 \%$ might progress toward a more severe degree of liver fibrosis. Also Derbala et al. (2011) reported that there is no effect of age, gender and serum alanine aminotransferase and aspartate aminotransferase levels on response to therapy in their patients.

On the other side Al Ashgar et al. (2009) reported that the lower Aspartate Transaminase (AST) levels as being associated with a higher odd of a sustained virological response. They also found that lower baseline serum AST and not ALT is an independent predictor of SVR to PEG-INF alfa-2a and RBV in patients with chronic HCV-4.

Platelets play a pivotal role in maintaining hemostatic competence. Thrombocytopenia, irrespective of its etiology, is associated with a risk for bleeding. In the present study blood platelets count showed significant 
relation with treatment response. Previous studies have shown that the low platelet count and splenomegaly is a pathognomonic sign of chronic liver disease so these patients will obviously show a poor response with interferon therapy. Khairy et al. (2012) reported that Low platelets count was associated with lower SVR level. This may be because lower platelet count is a hallmark of advanced fibrosis in chronic hepatitis $\mathrm{C}$ and has been reported to be associated with poor response to IFN. Also Ciesla et al. (2012) showed that assessment of the platelet level and the IL28B polymorphism can complement the decision-making algorithm for a patient's eligibility for antiviral therapy. but Del Campo et al. (2012) found no significant relation between platelets and Sustained Virological Response (SVR) in patients with HCV genotypes $1 \& 4$.

Important breakthroughs have been made in recent years into understanding the close interaction between Hepatitis C Virus (HCV) infection and glucose homeostasis. Both cross-sectional and longitudinal studies have demonstrated that infection with HCV is associated with an increased risk of developing insulin resistance and Type 2 diabetes. The interaction between $\mathrm{HCV}$ and glucose metabolism has significant clinical consequences. Insulin resistance and Type 2 diabetes not only accelerate the histological and clinical progression of chronic hepatitis $\mathrm{C}$, but also reduce the virological response to IFN- $\alpha$ based therapy (Kaddai and Negro, 2011).

In our study blood glucose showed significant relation with treatment response. In supporting to our result Giordanino et al. (2008) demonstrated that patients with chronic hepatitis $\mathrm{C}$ are at risk of developing type 2 Diabetes Mellitus (DM) and Impaired Fasting Glucose (IFG) and this risk may increase among Hepat0itis C Virus (HCV) patients not responding to an antiviral therapy. on other studies as Del Campo et al. (2012) found no significant relation between blood glucose level and Sustained Virological Response (SVR) in patients with genotypes $1 \& 4$.

\section{Conclusion}

Certain class II alleles can predict the response to HCV treatment, but a large scale study with big sample numbers is needed to settle the prevalent HLA alleles as well as other host genetic factors associated with responsiveness in the Egyptian population in order to select candidates for therapy and to reduce the exposure of non responders to the adverse effects of interferon treatment. Thus, HLA-DRB $1 * 07$, HLA-DRB $1 * 13$ and HLA-DQ02 alleles can predict the response to $\mathrm{HCV}$ combined therapy.

This study provide important pre-treatment predictive factors that could help the clinician to chose the most suitable and effective program and reduce complication.

\section{Limitation}

Small sample size limit of the emergence of some statistical relations significantly.

\section{Acknowledgment}

Thanks so much for Prof. Amal Idris, Head of Molecular Biology Unit, Fac. of Med., Benha Univ. Egypt.

\section{Author's Contributions}

Naglaa F. Alhusseini: Molecular biology technique, analysis and interpretation of data, contributed unpublished essential data, writing the manuscript and corresponding author.

Fathy M. Sary: Conception and design, analysis and interpretation of data.

Ashraf Kadry: Supervision on the research steps.

Heba Khairy: Collecting samples and clinical data, collecting the scientific materials and application of the experiment.

\section{Ethics}

We confirm that this manuscript has not been published elsewhere and is not under consideration by another journal. Each author confirms the manuscript represents honest work. All authors have approved the manuscript. Each author agrees with the order in which his name appears on the title page. Study design and methods were approved by Ethics Committee of Benha Faculty of Medicine.

\section{References}

Abdel-Rahman, M., M. El-Sayed, M. El Raziky, A. Elsharkawy and W. El-Akel et al., 2013. Co infection with hepatitis $\mathrm{C}$ virus and schistosomiasis: Fibrosis and treatment response. World J. Gastroenterol., 19: 2691-2696. DOI: 10.3748/wjg.v19.117.2691

Al Ashgar, H., A. Helmy, M.Q. Khan, K. Al Kahtani and M. Al Quaiz et al., 2009. Predictors of sustained virological response to a 48-week course of pegylated interferon alfa- $2 \mathrm{a}$ and ribavirin in patients infected with hepatitis C virus genotype 4. Ann. Saudi Med., 29: 4-14 PMID: 19139619

Alhusseini, N.F., M.Z. Abadeer and S.M. El-Taher, 2012. Hepatitis B virus DNA can be amplified directly from dried blood spot on filter paper. Am. J. Biochem. Biotechnol., 8: 143-149.

AGAI, 2006. American Gastroenterological Association Institute medical position statement on the management of gastric subepithelial masses. Gastroenterology, 130: 2215-2216. 
Baldo, V., T. Baldovin, R. Trivello and A. Floreani, 2008. Epidemiology of HCV infection. Curr. Pharm. Des., 14: 1646-1654. PMID: 18673187

Bhaskaran, K., I. Douglas, H. Forbes, I. dos-Santos-Silva and D.A. Leon et al., 2014. Body-mass index and risk of 22 specific cancers: A population-based cohort study of $5 \cdot 24$ million UK adults. Lancet, 384 : 755-65. DOI: 10.1016/S0140-6736(14)60892-8

Cavaillon, J.M., 2001. Pro-versus anti-inflammatory cytokines: Myth or reality. Cell Mol. Biol., 47: 695-702. PMID: 11502077

Ciesla, A., M. Bociaga-Jasik, I. Sobczyk-Krupiarz, M.K. Glowacki and D. Owczarek et al., 2012. IL28B polymorphism as a predictor of antiviral response in chronic hepatitis C. World J. Gastroenterol., 18: 4892-7. DOI: 10.3748/wjg.v18.i35.4892

Corghi, D.B., N.S. Goncales, S.B. Marques and J.R. Goncales, 2008. Distribution of the human leukocyte antigen class II alleles in Brazilian patients with chronic hepatitis $\mathrm{C}$ virus infection. Braz. J. Med. Biol. Res., 41: 884-889. PMID: 18925312

del Campo, J.A., M. Garcsa-Valdecasas, L. Rojas and M. Romero-Gómez, 2012. The hepatitis C virus modulates insulin signaling pathway in vitro promoting insulin resistance. PLoS One, 7: e47904-e47904.

DOI: 10.1371/journal.pone.0047904

Derbala, M.F., A.M. Amer, M. Almohanadi, A. John and A. Amin et al., 2011. Hepatitis C Genotype 4 with normal transaminases: Histological changes, schistosomiasis and response to treatment. J. Viral Hepat., 18: e258-e262. DOI: $10.1111 /$ j.1365-2893.2010.01403

Dienstag, J.L. and J.G. McHutchison, 2006. American gastroenterological association technical review on the management of hepatitis C. Gastroenterology, 130: 231-64. PMID: 16401486

Dienstag, J.L., 2002. The role of liver biopsy in chronic hepatitis C. Hepatology, 36: S152-S160. PMID: 12407589

EASL, 2011. Clinical practice guidelines: Management of hepatitis C virus infection. J. Hepatol., 55: 245-264. PMID: 21371579

EASL, 2014. Recommendations on treatment of hepatitis C. J. Hepatol., 61: 373-95. DOI: $10.1016 /$ j.jhep.2014.05.001

El-Chennawi, F.A., F.A. Auf, S.S. Metwally, Y.M. Mosaad and M.A. El-Wahab et al., 2008. HLAClass II Alleles in Egyptian patients with hepatocellular carcinoma. Immunol. Investigat., 37: 661-674. DOI: 10.1080/08820130802111605

El-Zanaty, F. and A. Way, 2009. Egypt Demographic and Health Survey 2008. Ministry of Health, ElZanaty and Associates and Macro International, Cairo.
Fanning, L.J., J. Levis, E. Kenny-Walsh, M. Whelton and K. O'Sullivan et al., 2001. HLA class II genes determine the natural variance of hepatitis $\mathrm{C}$ viral load. Hepatology, 33: 224-30. PMID: 11124840

Giordanino, C., E. Bugianesi, A. Smedile, A. Ciancio and M.L. Abate et al., 2008. Incidence of type 2 diabetes mellitus and glucose abnormalities in patients with chronic hepatitis $\mathrm{C}$ infection by response to treatment: Results of a cohort study. Am. J. Gastroenterol., 103: 2481-2487. DOI: $10.1111 / \mathrm{j} .1572-0241.2008 .02002$

Gomaa, H., M. Mahmoud, N. Saad, A. Saad-Hussein and E. Thabet et al., 2014. Impact of HLA-class I alleles on response to $\mathrm{HCV}$ treatment in a cohort of Egyptian patients. J. Genetic Eng. Biotechnol., 12: 61-64. DOI: 10.1016/j.jgeb.2014.03.004

Hasan, F., H. Asker, J. Al-Khaldi, I. Siddique and M. AlAjmi et al., 2004. Peginterferon alpha-2b plus ribavirin for the treatment of chronic hepatitis $\mathrm{C}$ genotype 4. Am. J. Gastroenterol., 99: 1733-7. PMID: 15330911

Hong, X., R.B. Yu, N.X. Sun, B. Wang and Y.C. Xu et al., 2005. Human leukocyte antigen class II DQB $1 * 0301$, DRB $1 * 1101$ alleles and spontaneous clearance of hepatitis $\mathrm{C}$ virus infection: A metaanalysis. World J. Gastroenterol., 11: 7302-7307. PMID: 16437632

Jiao, J. and J.B. Wang, 2003. Effects of HCV genotypes and HLA-DRB alleles on the response of chronic hepatitis $C$ patients to interferon alpha and libavilin. Zhonghua. Gan. Zang. Bing. Zhi., 11: 620-2. PMID: 14572343

Kaddai, V. and F. Negro, 2011. Current understanding of insulin resistance in hepatitis C. Expert Rev. Gastroenterol. Hepatol., 5: 503-516 PMID: 21780897

Kamal, S., M. Madwar, L. Bianchi, A.E. Tawil and R. Fawzy et al., 2000. Clinical, virological and histopathological features: long-term follow-up in patients with chronic hepatitis C co-infected with $S$. mansoni. Liver, 20: 281-289. PMID: 10959806

Kamal, S.M., A.A. El Tawil, T. Nakano, Q. He and J. Rasenack et al., 2005. Peginterferon alpha-2b and ribavirin therapy in chronic hepatitis $C$ genotype 4 : Impact of treatment duration and viral kinetics on sustained virological response. Gut, 54: 858-66. PMID: 15888797

Kamal, S.M. and I.A. Nasser, 2008. Hepatitis C genotype 4: What we know and what we don't yet know. Hepatology, 47: 1371-1383.

DOI: $10.1002 /$ hep. 22127

Khairy, M., M. Abdel-Rahman, M. El-Raziky, W. ElAkel and N. Zayed et al., 2012. Non-invasive prediction of hepatic fibrosis in patients with chronic HCV based on the routine pre-treatment workup. Hepat. Mon., 12: e6718-e6718.

DOI: $10.5812 /$ hepatmon.6718 
Lavanchy, D., 2011. Evolving epidemiology of hepatitis $\mathrm{C}$ virus. Clin. Microbiol. Infect., 17: 107-115. PMID: 21091831

Lee, S.S. and A.A. Abdo, 2003. Predicting antiviral treatment response in chronic hepatitis $\mathrm{C}$ : How accurate and how soon? J. Antimicrob. Chemother., 51: 487-91. PMID: 12615848

Martin, M.P. and M. Carrington, 2005. Immunogenetics of viral infections. Curr. OpinImmunol., 17: 510-516. PMID: 16084708

Martinetti, M., I. Pacati, M. Cuccia, C. Badulli and A. Pasi et al., 2006. Hierarchy of baby-linked immunogenetic risk factors in the vertical transmission of hepatitis $\mathrm{C}$ virus. Int. J. Immunopathol. Pharmacol., 19: 369-378. PMID: 16831303

Martinot-Peignoux, M., C. Stern, S. Maylin, M.P. Ripault and N. Boyer et al., 2010. Twelve weeks post treatment follow-up is as relevant as 24 weeks to determine the sustained virologic response in patients with hepatitis $\mathrm{C}$ virus receiving pegylated interferon and ribavirin. Hepatology, 51: 1122-6. DOI: 10.1002/hep.23444

Myers, R.P., A. Ramji, M. Bilodeau, S. Wong and J.J. Feld, 2012. An update on the management of chronic hepatitis $\mathrm{C}$ : Consensus guidelines from the Canadian association for the study of the liver. Can. J. Gastroenterol., 26: 359-375. PMID: 22720279

Nelson, D.R., Z. Tu, C. Soldevila-Pico, M. Abdelmalek and H. Zhu et al., 2003. Long-term interleukin 10 therapy in chronic hepatitis $\mathrm{C}$ patients has a proviral and anti-inflammatory effect. Hepatology, 38: 859-868. PMID: 14512873

Paladino, N., H. Fainboim, G. Theiler, T. Schroder and A.E. Muñoz et al., 2006. Gender susceptibility to chronic hepatitis $\mathrm{C}$ virus infection associated with interleukin 10 promoter polymorphism. J. Virol., 80: 9144-9150. PMID: 16940525

Poordad, F., J. McCone, Jr., B.R. Bacon, S. Bruno and M.P. Manns et al., 2011. Boceprevir for untreated chronic HCV genotype 1 infection. N Engl. J. Med., 364: 1195-1206.

DOI: $10.1056 /$ NEJMoa1010494

Rigopoulou, E.I., W.G. Abbott, P. Haigh and N.V. Naoumov, 2005. Blocking of interleukin-10 receptor-a novel approach to stimulate $\mathrm{T}$-helper cell type 1 responses to hepatitis $\mathrm{C}$ virus. Clin. Immunol., 117: 57-64. PMID: 16006191
Thio, C.L., 2008. Host genetic factors and antiviral immune responses to $\mathrm{HCV}$. Clin. Liver Dis., 12: 713-26. DOI: 10.1016/j.cld.2008.03. 002

Torre, F., S. Rossol, N. Pelli, M. Basso and A. Delfino et al., 2004. Kinetics of soluble Tumour Necrosis Factor (TNF)- $\alpha$ receptors and cytokines in the early phase of treatment for chronic hepatitis $\mathrm{C}$ : Comparison between interferon (IFN)- $\alpha$ alone, IFN $\alpha$ plus amantadine or plus ribavirin. Clin. Exp. Immunol., 136: 507-512. PMID: 15147353

Umemura, T., S. Joshita, S. Yoneda, Y. Katsuyama and T. Ichijo et al., 2011. Serum interleukin (IL)10 and IL-12 levels and IL28B gene polymorphisms: Pretreatment prediction of treatment failure in chronic hepatitis C. Antivir Ther., 16: 1073-80. DOI: 10.3851/IMP1869

Wang, L., H. Lin, T. Lee, Y. Wu and C. Hu et al., 2005. Human leukocyte antigen phenotypes and hepatitis C viral load. J. Clin. Virol., 32: 144-50. PMID: 15653417

Wawrzynowicz-Syczewska, M., J.A. Underhill, M.A. Clare, A. Boron-Kaczmarska and I.G. McFarlane et al., 2000. HLA class II genotypes associated with chronic hepatitis $\mathrm{C}$ virus infection and response to alpha-interferon treatment in Poland. Liver, 20: 234-239. PMID: 11124840

Yee, H.S., M.F. Chang, C. Pocha, J. Lim and D. Ross et al., 2012. Update on the management and treatment of hepatitis $\mathrm{C}$ virus infection: Recommendations from the department of veterans affairs hepatitis $\mathrm{C}$ resource center program and the national hepatitis $\mathrm{C}$ program office. Am. J. Gastroenterol., 107: 669-89. DOI: 10.1038/ajg.2012.48

Yosry, A., R. Fouad, S. Mahmoud, M. El-Raziky and A. El-Hennawy et al., 2011. The association of HLA class II DR B1 alleles with HCV infection in Egyptian children. Arab J. Gastroenterol., 12: 25-28. DOI: 10.1016/j.ajg.2011.01.007

Zeuzem, S., P. Andreone, S. Pol, E. Lawitz and M. Diago et al., 2011. Telaprevir for retreatment of HCV infection. N Engl. J. Med., 364: 2417-2428. DOI: $10.1056 /$ NEJMoa1013086

Zhang, L.J. and X.Z. Wang, 2006. Interleukin-10 and chronic liver disease. World J. Gastroenterol. 12: 1681-5. PMID: 16586534 